\title{
Stochastic Estimation of Acoustic Impedance of Glass-Reinforced Epoxy Coating
}

\author{
Nohyu $\mathrm{Kim}^{\dagger}{ }^{\dagger}$ and Hwan-Seon Nah**
}

\begin{abstract}
An epoxy coating applied to the concrete surface of a containment building deteriorates in hazardous environments such as those containing radiation, heat, and moisture. Unlike metals, the epoxy coating on a concrete liner absorbs and discharges moisture during the degradations process, so it has a different density and volume during service. In this study, acoustic impedance was adopted for characterizing the degradation of a glass-reinforced epoxy coating using the acoustic reflection coefficient (reflectance) on a rough epoxy coating. For estimating the acoustic reflectance on a wavy epoxy coating surface, a probabilistic model was developed to represent the multiple irregular reflections of the acoustic wave from the wavy surface on the basis of the simulated annealing technique. A number of epoxy-coated concrete specimens were prepared and exposed to accelerated aging conditions to induce an artificial aging degradation in them. The acoustic impedance of the degraded epoxy coating was estimated successfully by minimizing the error between a waveform calculated from the mathematical model and a waveform measured from the surface of the rough coating.
\end{abstract}

Keywords: Epoxy Coating, Ultrasonic Test, Material Degradation, Nuclear Power Plant, Aging Epoxy

\section{Introduction}

A containment building is a steel or reinforced concrete structure enclosing a nuclear reactor. Fig. 1 shows a sectional view of the reactor building of CANDU 6 nuclear plant at Wolsung in Korea. While the containment plays a critical role in the most severe nuclear reactor accidents, it is also designed to contain or condense steam in the short term for large break accidents. Containment consists of a pre-stressed concrete structure with a domed roof, a dousing system, airlocks and a closure system.

A dousing tank located in the dome of the containment building holds light water for both dousing and medium pressure emergency coolant injection. With the dousing valves open, water flows by gravity from the storage tank to the spray headers to cause dousing. Dousing con- denses the released steam and thus absorbs the heat energy in the steam, reduces the magnitude and duration of the containment overpressure pulse, and dissolves soluble fission products, and entrains insoluble fission products minimizing the airborne spread of contamination.

Epoxy coating has been applied to internal surfaces of concrete containment structures of nuclear power plants to seal the structure and protect from radiation, moisture and leakage of the contaminant. The coating material is a special type of epoxy resin which has a strong resistance to strong radiation, leakage, and water. Although the epoxy coating is designed and constructed to be proof against 30-40 years of operation in compliance with the related standard regulations, it degrades during service due to aging, radiation, heat, and water generated in the containment structure. Several forms of material

[Received: December 16, 2013, Revised: December 30, 2013, Accepted: December 30, 2013] *School of Mechatronic Engineering, Korea University of Technology and Education, Byungchun-myun, Chunan, Chungnam 330-860, Korea, **Structural Engineering Lab., Korea Electric Power Research Institute, 103-16 Munji-dong, Yusung-gu, Daejeon, 305-380, Korea †Corresponding Author: nykim@koreatech.ac.kr

(c) 2014, Korean Society for Nondestructive Testing 
deterioration have been reported and led to severe material damages such as delamination, blistering, and breakage of the coating layer $[1,2]$. However, the management and maintenance of epoxy coating in nuclear power plant has been done by visual inspection.

In order to extend the life of the coating and to strengthen the mechanical property of the coating, a glass-reinforced epoxy coating was developed and evaluated in this work to investigate the degrading characteristics of the reinforced epoxy coating. A limited number of papers have been reported on the evaluation of the degradation of reinforced epoxy resin including the destructive and nondestructive methods such as TGA (thermo-gravimetric analysis), adhesion force test, and ultrasonic testing. Out of these techniques, the ultrasonic nondestructive method has been considered as the most effective method because it is relatively fast and sensitive to the material degradation. Traditional ultrasonic technique for the evaluation of material degradation uses the dependency of the velocity and attenuation of the ultrasound on material property [3]. Surface wave or plate wave are also adopted as an alternatives to bulk waves for the layered structure. However, unlike metals, it is hard to measure the ultrasonic velocity or energy loss with good accuracy due to a wavy epoxy coating surface of the concrete liner as shown in Fig. 1. Moreover its material properties change drastically during aging process mainly because it absorbs and/or discharges moisture from outside combined with chemical chain reaction by heat. This particular characteristic makes it difficult the measurement of acoustic velocities in usual ultrasonic methods which are applied successfully to metals using time-offlight (TOF). One of the most reliable and versatile ultrasonic methods to measure the acoustic wave velocity is $\mathrm{V}(\mathrm{z})$ curve, which utilizes surface acoustic wave (SAW) produced by focused ultrasound in scanning acoustic microscope (SAM) to characterize material property. Many results including Kim [4] has been reported with success to determine mechanical properties such as Young's modulus and microstructural characteristics based on $\mathrm{V}(\mathrm{z})$ curve from SAM. Although it is quite applicable to most materials, it is limited to the material's surface by the exponential decay of sound energy through the material depth. Epoxy polymer coating is not only wavy, but also interacts with heat and moisture and change in density and mechanical property. Thus V(z) curve may indicate a false alarm to the aging state of the epoxy coating and does not represent the overall status of degradation of epoxy resin.

This paper describes an ultrasonic method for material characterization using acoustic impedance to investigate aging degradation of glass-reinforced epoxy coating. The acoustic impedance gives more accurate and overall

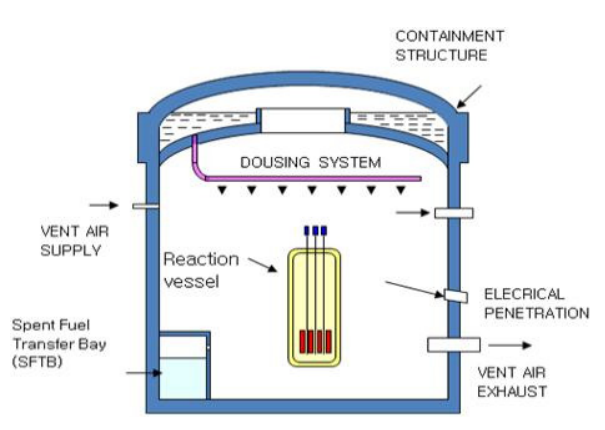

(a)

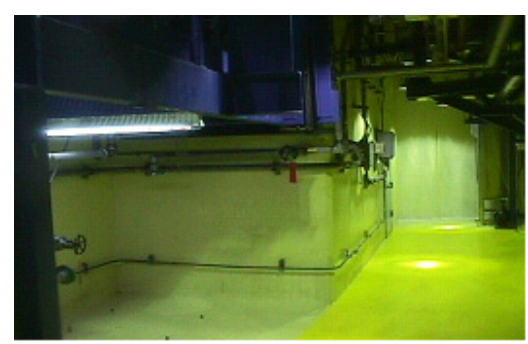

(b)

Fig. 1 Epoxy coating of, (a) containment structure(CANDU), and (b) Wolsung nuclear power plant 
information about material property than acoustic velocity alone. To analyze the aging characteristics of epoxy coating, a probabilistic method was also developed to determine the acoustic impedance using a multiple reflection waves from the wavy surface based on simulated annealing technique. A number of epoxy coated concrete specimens were constructed and exposed to accelerated aging conditions to produce the artificial aging effects in the epoxy and to measure the acoustic impedance. Acoustic impedance of the aging epoxy coating was estimated with success during accelerated aging test by the reflectance of ultasound on the coating surface.

\section{Statistic Model of Acoustic Reflection on a Wavy Epoxy Surface}

Epoxy coating on concrete liner in containment building of nuclear power plant has a wavy rough surface as shown in Fig. 2(a). When a contact-type ultrasonic transducer is placed on the epoxy coating surface for inspection as in Fig. 2(b), a planar ultrasound incident to the wavy epoxy coating reflects back to the transducer with arbitrary phase due to depth difference and irregular reflection.

Moreover, the reflected waves bounce back and forth multiple times in a very thin coupling layer between the coating and transducer, so that the resultant waveform of ultrasound changes and distorts leading to a measurement error.

In order to consider this irregular reflection of ultrasound, a statistical model was developed to calculate the multiple irregular reflection of ultrasound on a layered structure. In this model described in Fig. 3, the epoxy coating was assumed as three layered structure composed of the couplant, coating, and concrete substrate.

It has an ideal one-dimensional flat surface which ensures a perfectly normal and planar reflection of acoustic wave, but allows a random

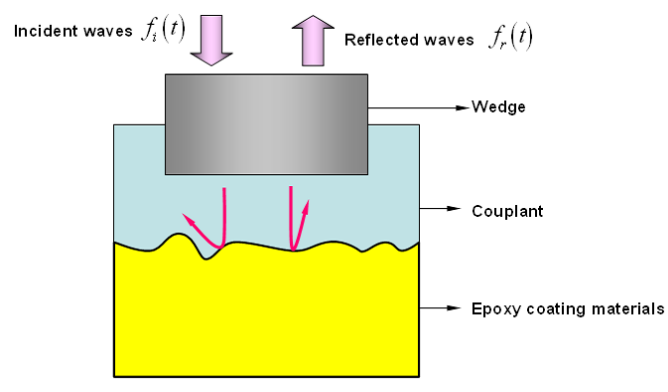

(a)

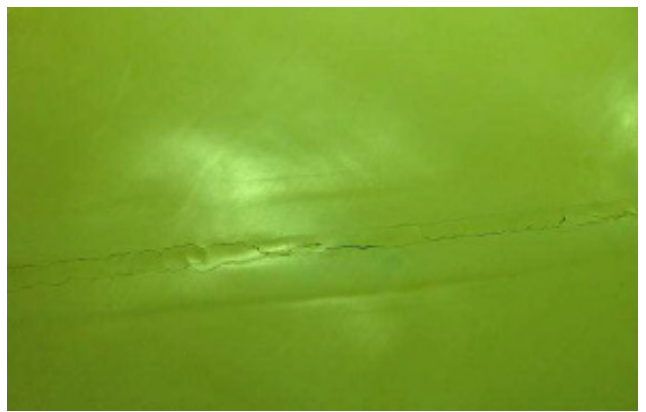

(b)

Fig. 2 Irregular reflection of acoustic wave, (a) on a wavy epoxy coating, and (b) epoxycoated concrete liner of nuclear power plant

phase variation at every reflection on the coating surface. Fig. 3 describes in detail the mathematical model and multiple reflections produced on the epoxy coating surface by an incident ultrasonic wave, $f_{i}(t)$ from the transducer. Assuming that the thickness of the couplant layer is small comparing to the coating layer and wavelength of ultrasound propagating without energy loss and irregular reflection, total reflection wave, $f_{r}(t)$, from the epoxy coating surface can be expressed by [5-7]

$$
\begin{aligned}
& f_{r}(t)=R_{12} f_{i}(t)+\frac{T_{12} T_{21}}{R_{21}} \sum_{m=1}^{\infty}\left[\left(R_{21} R_{23}\right)^{m} f_{i}(t-2 m s d)\right] \\
& R_{23}=\frac{Z_{3}-Z_{2}}{Z_{3}+Z_{2}}, \quad T_{23}=\frac{2 Z_{3}}{Z_{3}+Z_{2}} .
\end{aligned}
$$

where $R_{12}, R_{23}, T_{12}, T_{23}$ are the reflection and transmission coefficients between the layers corresponding to the subscript numbers, $s$ is the 


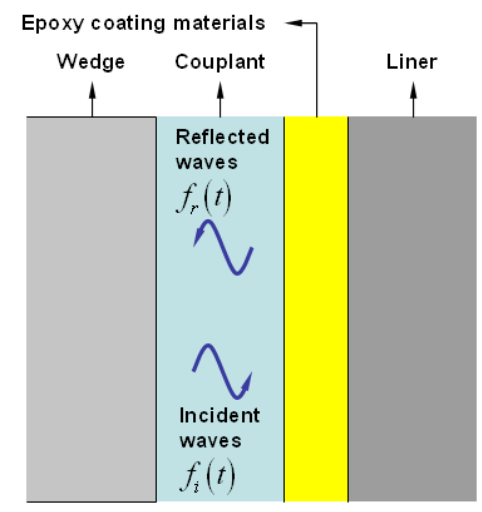

(a)

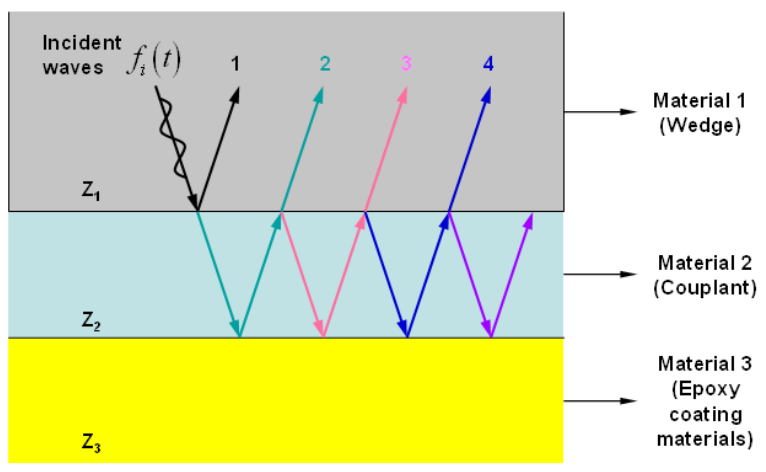

(b)

Fig. 3 Reflection on epoxy surface, (a) layered structure model, and (b) multiple acoustic reflections inside a couplant layer

slowness of the ultrasound in each layer, $d$ the distance from the transducer and the coating layer, $Z_{1}, Z_{2}, Z_{3}$ the acoustic impedance of each layer. The model in Fig. 3 and Eq. (1) is valid only if the interface surface between the couplant and the epoxy resin is flat and the wavelength of ultrasound is much larger than the roughness of the surface. Since the epoxy coating surface is wavy and irregular, a complicated reflections occur at the surface, so that this effect of the wavy surface on the reflection wave should be taken into account. A probabilistic logic is introduced to the ideal reflection model described in Fig. 3 to consider the waviness of the epoxy coating for the accurate evaluation of acoustic impedance. By this statistical approach, random variables are introduced to describe a nondeterministic characteristics of surface waviness and the complex irregular multiple reflections. In the deterministic model of Fig. 3, the phase difference of each multiple reflection wave 2, 3, $4 \ldots$ is same and explicitly given by the timeof-flight $s d$ inside the couplant layer. But in the probabilistic model, the phase change of the reflection waves is arbitrary at each reflection. Thus it was set as a random variable, which is a random phase delay $\phi$ generated by the surface waviness of epoxy coating. In this statistical model, the mean gap-distance from the transducer wedge to the epoxy coating surface, $\underline{d}$, in Fig. 3(b), is also treated as a variable because it changes according to the surface waviness of the epoxy coating or a testing condition like contact pressure.

The random variable $\phi$ was assumed in this work to have a probability distribution function, $\mathrm{p}(\phi)$, which is dependent upon the characteristics of the surface of the epoxy coating. Therefore, the resultant reflection wave $f_{r}(t)$ for the wavy epoxy coating layer can be expressed with the random variables as following

$$
f_{r}(t)=R_{12} f_{i}(t)+\frac{T_{12} T_{21}}{R_{21}} \sum_{m=1}^{\infty}\left[\left(R_{21} R_{23}\right)^{m} \int_{-\infty}^{\infty} f_{i}(t-2 m s \underline{d}+\phi) p(\phi) d \phi\right]
$$

Based on the Eq. (3), the reflection coefficient $R_{23}$ can be calculated using simulated annealing(SA) optimization technique from the reflection wave $f_{r}(t)$ measured in experiment to determine the acoustic impedance of epoxy coating for the evaluation of degradation, which is simply given by basic acoustic theory, $R_{23}=\frac{Z_{3}-Z_{2}}{Z_{2}+Z_{3}}$. 


\section{Evaluation of Acoustic Impedance Using SA Method}

In order to determine the acoustic impedance $Z_{3}$ of epoxy coating, the reflection coefficient $R_{23}$ was calculated first by the probabilistic model and the optimization technique in Eq. (3) using the measured waveforms, $f_{i}(t)$ and $f_{r}(t)$ in experiment. Then the acoustic impedance was obtained from the relationship between the reflection coefficient and the acoustic impedance. The objective for optimization based on SA algorithm is the mean square value of an error between the computed reflection wave $f_{r}(t)^{s}$ of theoretical model in Eq. (3) and the measured wave $f_{r}(t)^{m}$ in experiment such as

$$
\operatorname{Minimize}\left(\text { Error }=\sqrt{\sum\left[\text { Measurement }^{2}-\text { Calculation }^{2}\right]}\right) .
$$

The probability density function $\mathrm{p}(\phi)$ of the random variable $\phi$ representing the surface waviness was assumed to have Gaussian distribution with zero mean. The variance of $\phi$ and the mean distance $\underline{d}$ were chosen randomly during optimization process in SA routine to minimize the objective. The larger value of the variance of $\phi$ indicates that the surface of the epoxy coating is rougher and wavier. Simulated annealing(SA) is the process of raising the temperature, which is a measure of the internal energy, of a material and then slowly cooling it to allow it to reach its lowest energy state.

SA emulates this process in an attempt to find the global optimum of an objective, or "energy" function. The optimization process starts with a random configuration $p_{k}^{i}$ at $\mathrm{k}$-th step then measures its cost. The next state at $k+1$ is determined using

$$
p_{k+1}^{i}=p_{k}^{i}+y^{i}\left(B^{i}-A^{i}\right)
$$

where $y^{i}$ is a random variable that takes on value between -1 and 1 , and $B^{i}$ and $A^{i}$ are the upper and lower limits for the i-th parameter, respectively. Then, the new configuration is checked to insure that it satisfies the constraints. SA guarantees a global optimum for the optimization problems with a number of random variables and allows for the globally optimum region to be found quickly.

\section{Specimen of Glass-Reinforced Epoxy Coating}

Concrete cubes of $50 \mathrm{~mm} \times 50 \mathrm{~mm} \times 50 \mathrm{~mm}$ were made out of $19 \mathrm{~mm}$ aggregate and type 5 cement same as used for nuclear power plants. Curing temperature was $10^{\circ} \mathrm{C}$ according to the standard for concrete casting in winter. Cured concrete specimens were ground to remove surface defects like concave-convex and laitance, and filled with epoxy grout to remove holes.

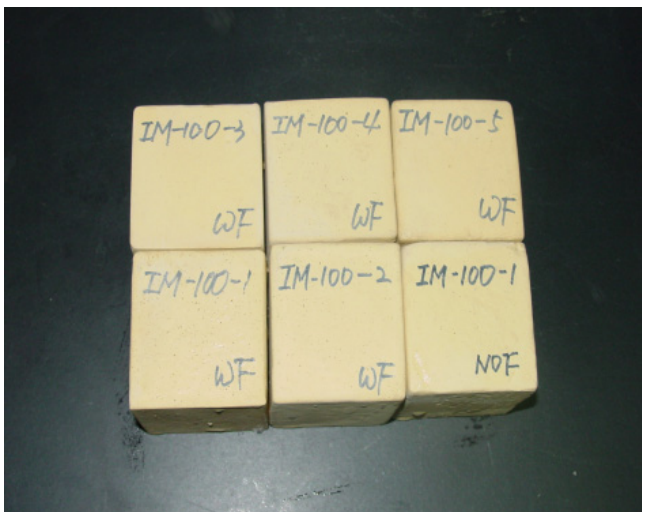

(a)

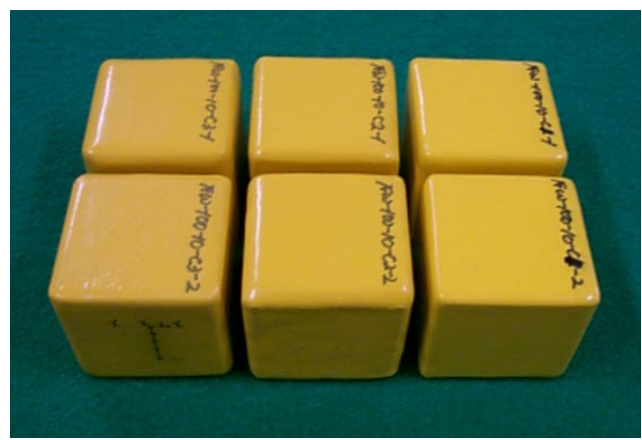

(b)

Fig. 4 Concrete specimens, (a) glass-reinforced coating, and (b) normal coating without glass fiber 
After conditioning, a special epoxy resin (domestic K company) was coated to the concrete specimen. Two kinds of coating were applied to the concrete specimen for comparison. One was a glass-reinforced epoxy, and the other was a nominal epoxy without glass fiber. The glasseinforced epoxy is nothing but a mixture of fine chips of glass fiber and epoxy resin, a similar epoxy applied to Wolsung nuclear power plant. When it was coated in accordance with the original specification requirements, the air temperature was maintained at $18^{\circ} \mathrm{C}$ and the water content of the concrete surface was kept within the range of $6 \%$. At first $1^{\text {st }}$ primer EP1120 was applied and ET 5140 epoxy paints were applied next two to five times. Each coating was deposited to be approximately $0.075-0.125 \mathrm{~mm}$ so as to have $0.5-0.7 \mathrm{~mm}$ in total thickness after minimum 3 days of curing at atmosphere temperature. The concrete specimens after epoxy coating are shown as in Fig. 4.

\section{Accelerated Aging Test of Epoxy Coating}

Major factors causing the degradation of epoxy coating are the exposure to radiation, heat, and moisture. From previous studies and preliminary aging test, water was found as a dominant parameter that can develop the delamination and swelling of the coating. Along with the water, the temperature of the epoxy is also important to material degradation of epoxy coating because heat accelerates the aging process. Thus the aging test was performed in a hot water tank. In the tank, the specimens were immersed as shown in Fig. 5, and the temperature of the tank was controled electrically. Table 1 lists the aging conditions and the types of specimens used in the experiment. At each step of aging time from $0,8,16,24,32$, and 64 days, three specimens of same type were picked out of immersion tank and cooled down to atmosphere temperature to measure acoustic impedance. After

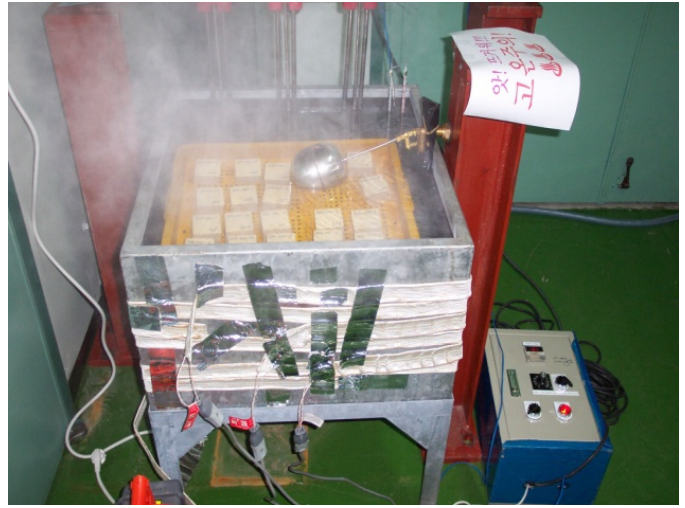

Fig. 5 Accelerated aging apparatus for epoxy coated specimens

Table 1 Types of specimens and aging conditions

\begin{tabular}{|c|c|c|c|c|}
\hline \multicolumn{3}{|c|}{ Aging Condition } & \multirow{2}{*}{\multicolumn{2}{|c|}{$\begin{array}{c}\text { Types of specimens } \\
\text { Epoxy } \\
\text { (approximately } 1.0 \mathrm{~mm} \\
\text { in thickness) }\end{array}$}} \\
\hline \multirow{2}{*}{$\begin{array}{l}\text { Moisture } \\
\text { condition }\end{array}$} & \multirow{2}{*}{$\begin{array}{c}\text { Temperature } \\
\text { condition }\end{array}$} & \multirow{2}{*}{$\begin{array}{l}\text { Coating } \\
\text { type }\end{array}$} & & \\
\hline & & & $\begin{array}{l}\text { Exposure } \\
\text { time }\end{array}$ & Specimen \\
\hline \multirow{2}{*}{$\begin{array}{l}\text { Immersion } \\
\text { in } \\
\text { pure water }\end{array}$} & \multirow{2}{*}{$100^{\circ} \mathrm{C}$} & $\begin{array}{l}\text { Glass } \\
\text { reinforced }\end{array}$ & $\begin{array}{c}0 \text { day } \\
8 \text { days } \\
16 \text { days } \\
32 \text { days } \\
48 \text { days } \\
64 \text { days }\end{array}$ & $\begin{array}{l}\text { IM-100-\#1-WF } \\
\text { IM-100-\#2-WF } \\
\text { IM-100-\#3-WF }\end{array}$ \\
\hline & & $\begin{array}{l}\text { No glass } \\
\text { fiber }\end{array}$ & $\begin{array}{c}0 \text { day } \\
8 \text { days } \\
16 \text { days } \\
32 \text { days } \\
48 \text { days } \\
64 \text { days }\end{array}$ & $\begin{array}{l}\text { IM-100-\#1-NOF } \\
\text { IM-100-\#2-NOF } \\
\text { IM-100-\#3-NOF }\end{array}$ \\
\hline
\end{tabular}

the measurement of acoustic impedance, the specimens were put back to the immersion tank for further artificial aging test.

\section{Experimental Results}

Fig. 6 shows the experimental setup to measure the acoustic impedance of the specimens. A contact type $10 \mathrm{MHz}$ ultrasonic transducer (Panametrics A130) was attached through a delay line to generate and receive acoustic waves from the surface of epoxy coating specimen in a small water container. In the experiment, as described in Table 1, three specimens of each 
type (glass-fibered epoxy and nomal epoxy, IM-100-\#1, \#2, \#3 in Table 1) were subject to the same aging condition to get a more reliable test results. Also five different measurement points on the surface of specimen were tested and averaged to obtain a mean value of acoustic impedance for the specimen. Fig. 7(a) shows

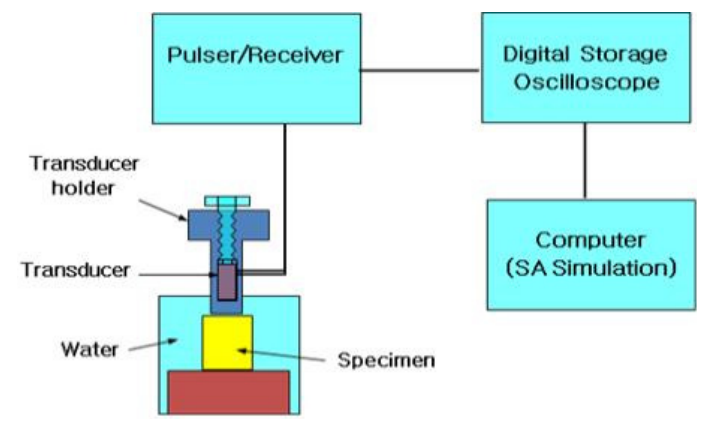

one example of incident and reflected waveforms captured in experiment, which are $f_{i}(t)$ and $f_{r}(t)$ respectively presented in Eq. (1). In Fig. 7(a), it can be seen clearly that two waveforms are different due to multiple reflections on epoxy coating. By changing the random variables defined in the statistic model in Eq. (3), the

Fig. 6 Experimental configuration for acoustic impedance measurement

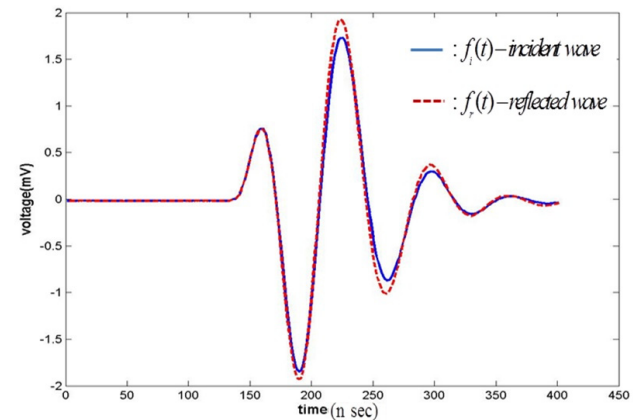

(a)
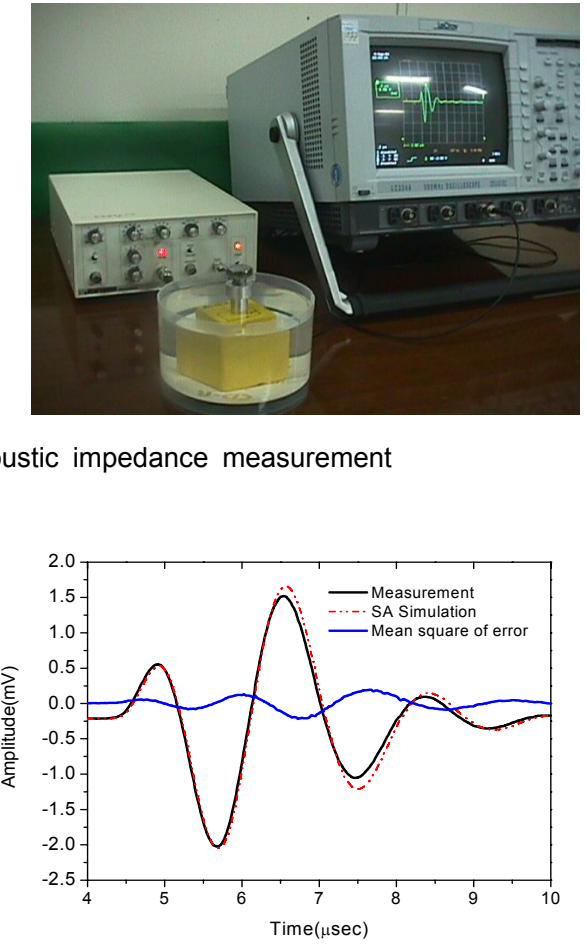

(b)

Fig. 7 Waveform of reflected waves, (a) acoustic waves from epoxy specimen of 8 days of aging time, and (b) an error between computation and experiment during SA optimization

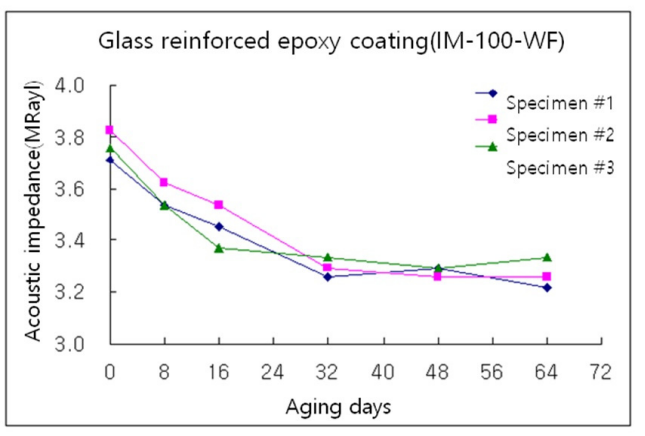

(a)

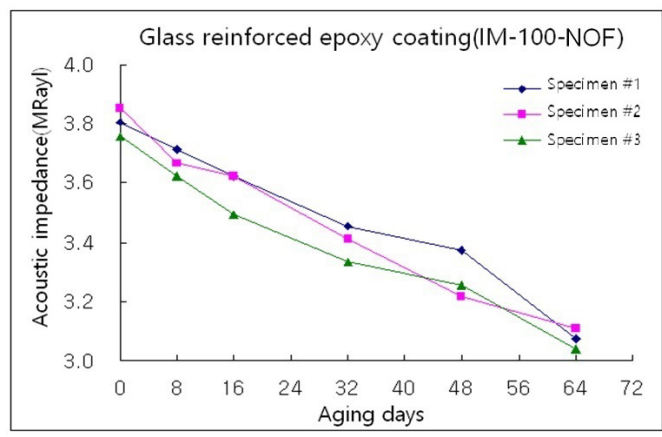

(b)

Fig. 8 Variation of acoustic impedance of epoxy coating specimens, (a) with glass-fiber, and (b) without glass-fiber 
mean square value of an error between the simulated reflection wave $f_{r}(t)^{s}$ and the measured wave $f_{r}(t)^{m}$ was minimized as described in Fig. 7(b). Calculation results for acoustic impedance of epoxy coatings are shown in Fig. 8, where each data point represents an average value of three specimens of the same epoxy type. While Fig. 8(a) represents the variation of acoustic impedance of conventional coating specimen as the aging time increases, Fig. 8(b) describes that of the glass-reinforced epoxy coating. Horizontal axis of Fig. 8 indicates the period of aging in days from zero to 64 days, and vertical one means the acoustic impedance. It is observed from Fig. 8 that, no matter what type of the coating is, acoustic impedance tends to decrease with aging time under the heat and moisture attack.

The conventional epoxy coating shows a monotonic decrease in acoustic impedance as the aging time increases. However, the acoustic impedance of the glass-reinforced epoxy coating decreases at first until 32 days, but does not decrease any further beyond 32 days. It has almost the same acoustic impedance values as low as $3.2 \times 10^{6} \mathrm{Kgm}^{2} /$ sce after 32 days. Therefore it can be concluded that the glass fiber in epoxy coating prevents epoxy resin from absorbing moisture in the presence of heat and moisture, and delays the degrading process of epoxy resin. It is also found that the acoustic impedance is a good indicator to the state of material degradation of epoxy coating in containment building.

\section{Conclusions}

Degradation of glass-reinforced epoxy coating caused by heat and moisture in nuclear power plant was estimated using acoustic impedance by a probabilistic model for irregular multiple reflections on the coating. The model was proved in experiment to be accurate enough to describe the complicated multiple reflections of the ultrasound, and effective to estimate the degradation of epoxy coating when combined with the SA technique. From the experimental results obtained by accelerated aging tests, the followings are concluded:

1) Contrary to metals, the acoustic impedance value of glass reinforced epoxy coating had changed up to approximately $20 \%$. It is partly because the acoustic velocity of epoxy resin changes, and the density of epoxy resin changes due to water and heat. As the aging process proceeded, the acoustic impedance decreased with accelerated aging time. It indicates that the acoustic impedance is useful to investigate or monitor the degradation and the remaining life of epoxy coating in aging nuclear power plants.

2) The technique suggested in the paper is simple and fast because it measures the acoustic impedance of epoxy coating by just contacting the transducer on the coating surface. It may provide a powerful inspection tool for in-situ application in nuclear power plants.

3) Glass-reinforced epoxy coating had a higher value of acoustic impedance than the normal epoxy coating when subject to accelerated aging test. In the beginning of accelerated aging period, it indicated the same strong decrease in acoustic impedance as the normal epoxy coating, but it did not change any more after 32 days. It is guessed that the glass fiber may block the permeation of moisture and heat diffusion into epoxy resin.

\section{Acknowledgements}

This work was supported by Radiation Technology R\&D program through the National Research Foundation of Korea funded by the Ministry of Science, ICT \& Future Planning 
NRF-2013M2A2A9043274, and Research Promotion Fund of Korea University of Technology and Education.

\section{References}

[1] H. Nah, N. Kim, K.-J. Kwon and Y.-C. Song, "Experimental evaluation on degradation characteristics of epoxy coating by using adhesion force and impedance," Experimental Mechanics, Vol. 7, No. 2, pp. 149-158 (2003)

[2] N. Kim and H. Nah, "Ultrasonic evaluation of epoxy coating in nuclear power plant," Material Science Forum, Vol. 449452, pp. 1209-1212 (2004)

[3] M. Frigione and A. Maffezzoli, "Nondestructive and in-situ monitoring of mechanical property buildup in epoxy adhesives for civil applications by propagation of ultrasonic waves," Ploymer Engineering and Science, Vol. 40, No. 3, pp. 656-664 (2000)
[4] N. Kim, H. S. Nah and S. S. Lee, "Characterization of material degradation in epoxy film based on scanning acoustic microscopy (SAM)," Key Engineering Materials, Vol. 321-323, pp. 578-581 (2006)

[5] N. Kim and B. Moon, "A new technique for ultrasonic thickness measurement of thin film," Japan and Korea Joint Workshop on Advanced Semiconductor Processing and Equipments, pp. 136-141, Hakone, Japan (2003)

[6] V. K. Kinra and V. Dayal, "A new technique of ultrasonic nondestructive evaluation of thin specimens," Experimental Mechanics, Vol. 28, No. 3, pp. 288-297 (1988)

[7] V. K. Kinra and V. R. Iyer, "Ultrasonic measurement of the thickness, phase velocity, density or attenuation of a thin viscoelastic plate. Part I: the forward problem," Ultrasonics, Vol. 33, No. 2, pp. 95-109 (1995) 